\title{
PENGARUH PELATIHAN DAN DISIPLIN KERJA TERHADAP KINERJA KARYAWAN PADA PT. SANY TOGA GEMILANG
}

\author{
Oleh : \\ Overagus Sibagariang ${ }^{1)}$, Togi Manalu ${ }^{2)}$, dan Wulan Sari Girsang ${ }^{3)}$ \\ Universitas Prima Indonesia, Medan ${ }^{1,2,3)}$ \\ E-Mail:

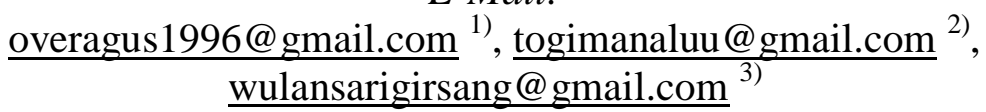

\begin{abstract}
Employee performance is the level of success of employees in carrying out their duties. Factors that influence employee performance are training and discipline. Training is an activity prepared by management to improve the employees' skills and abilities to produce high performance. Discipline is the awareness and availability of a person to obey all applicable rules and social norms. The employee's performance decreases due to the poor discipline and inappropriate training programs. PT. Sany Toga Gemilang is engaged in the plastic industry. The research method used is a quantitative approach, the type of research used is quantitative descriptive. Data collection is done by having interviews, questionnaires and documentation studies. Analysis of the data used is multiple linear regressions. The population is all employees (186 people). Slovin formula was used in determining the research sample, where 127 people were obtained as the study sample, while for testing the validity taken a sample of 30 people outside the study sample. The results showed that training and discipline simultaneously and partially have a positive and significant effect on employee's performance with a determinant coefficient of 0.767 or $76.7 \%$, while the remaining $23.3 \%$ was not examined. The conclusion of the study is that simultaneously and partially training and discipline have a significant effect on employee's performance at PT. Sany Toga Gemilang.
\end{abstract}

\section{Keywords: Training, Discipline, Performance}

\section{PENDAHULUAN}

Karyawan pada hakekatnya merupakan salah satu sumber daya terpenting dalam sebuah organisasi atau perusahaan. Sumber daya inilahyang memegang peran penting sejauh mana perusahaan akan berkembang. Jadi dapat dikatakan bahwa perusahaan sangat bergantung pada kinerja karyawannya, dan karyawan tentu akan memberi kinerja yang baik secara terus menerus hanya jika mereka memiliki kemampuan dan keterampilan yang baik. Jika karyawan merasa puas dan senang bekerja pada perusahaan, tentu mereka akan memberikan loyalitas yang tinggi serta berusaha meningkatkan kemampuan dan keterampilan yang dimilikidalam mencapai tujuan yang telah ditetapkan perusahaan. Oleh sebab itu setiap karyawan harus berusaha semaksimal mungkin untuk memberikan kinerja yang tinggi bagi perusahaan agar dapat merealisasikan hal tersebut. 
Kinerja karyawan dapat dipengaruhi oleh beberapa faktor seperti kepemimpinan dalam perusahaan, seleksi, kompensasi, lingkungan kerja, pelatihan, dan lain-lain.Salah satu diantaranya adalah pelatihan karyawan. Perusahaan perlu membekali karyawan dengan melakukan program pelatihan untuk meningkatkan keterampilan dan pengetahuan karyawan untuk memberi semangat dan motivasi bagi para karyawan dengan adanya rasa kepedulian atas kinerjanya serta mengetahui sejauh mana keberhasilannya dalam menjalankan tugas dan tanggungjawabnya.

$\begin{array}{lcr}\begin{array}{l}\text { Hubungan } \\ \text { menyenangkan }\end{array} & \text { kerja } & \text { yang } \\ \text { memperbaiki } & \text { semangat } & \text { dan }\end{array}$
kesungguhan kerja akan mempengaruhi kinerja karyawan. PT. Sany Toga Gemilang Medan merupakan perusahaan yang bergerak dibidang industri produk jenis plastik. Perusahaan ini berada di Jalan Setia Luhur No. 188 A-B, (TOGA CENTRE), Dwikora, Medan Helvetia. Dalam menjalankan usahanya, perusahaan berusaha meningkatkan kinerja karyawan guna mewujudkan tujuan perusahaan. Namun hal tersebut belum sepenuhnya dapat terpenuhi dilihat dari kinerja karyawan yang masih rendah.

Berdasarkan latar belakang yang telah diuraikan sebelumnya, makapeneliti mengidentifikasi masalahnya adalah:

1. Pelatihan yang dilakukan pimpinan perusahaan PT. Sany Toga Gemilang Medan dinilai masih kurang efektif yang dapat dilihat dari masih banyak karyawan yang tidakhadir pada saat mengikuti pelatihan.

2. Disiplin karyawan pada PT. Sany Toga Gemilang Medan masih rendah,karena kurangnya ketegasan dan sanksi hukuman yang diberikan.

3. Kinerja karyawan pada PT. Sany Toga Gemilang Medan masih rendah, terlihat dari hasil penjualan yang tidak tercapai.

Adapun masalah yang dipaparkan dalam penulisan skripsi ini adalah:

1. Bagaimana pengaruh pelatihan terhadap kinerja karyawan pada PT. Sany Toga Gemilang Medan?

2. Bagaimana pengaruh disiplin terhadap kinerja karyawan pada PT. Sany Toga Gemilang Medan?

3. Bagaimana pengaruh pelatihan dan disiplin terhadap kinerja karyawan pada PT. Sany Toga Gemilang Medan?

\section{METODE PELAKSANAAN}

Menurut Bangun (2012:201), "Pelatihan adalah proses untuk mempertahankan atau memperbaiki keterampilan karyawan untuk mengahasilkan perkerjaan yang efektif."

Menurut Handoko (2014:104), "Menyebutkanpelatihan (training) dimaksudkan untuk memperbaiki penguasaan berbagai keterampilan dan teknik pelaksanaan kerja tertentu, terinci dan rutin".

Menurut

Mangkunegara

(2013:44), indikator pelatihan:

1. Tujuan dan sasaran pelatihan dan pengembangan harus jelas dan dapat diukur.

2. Para pelatih (trainer's) harus memiliki kualifikasi yang memadai.

3. Materi pelatihan dan pengembangan harus disesuaikan dengan tujuan yang hendak dicapai.

4. Metode pelatihan dan pengembangan harus sesuai dengan tingkat kemampuan pegawai yang menjadi peserta. 
5. Peserta pelatihan dan pengembangan (trainer) harus memenuhi persyaratan.

Menurut zainal, dkk (2014:599), adalah suatu alat yang digunakan para manager untuk berkomunikasi dengan karyawan agar mereka bersedia untuk mengubah suatu perilaku serta sebagai suatu upaya untuk meningkatkan dan norma-norma sosial yang berlaku.

Menurut Sinambela (2016:335), displin kerja adalah kesadaran dan kesediaan pegawai menaati peraturan organisasi dan norma-norma sosial yang berlaku.

Menurut Hasibuan (2016:194-198), indikator yang mempengaruhi tingkat kedisplinan karyawan suatu organisasi, diantaranya sebagai berikut.

1. Tujuan dan kemampuan

2. Teladan pemimpin

3. Balas jasa

4. Keadilan

5. Waskat

6. Sanksi hokum

7. Ketegasan

8. Hubungan kemanusiaan

Menurut Sutrisno (2010:172), "kinerja adalah hasil kinerja karyawan dilihat pada aspek kualitas, kuantitas, waktu kerja dan kerja sama untuk mencapai tujuan yang telah ditetapkan oleh organisasi".

Menurut Sutrisno (2018:171), keberhasilan organisasi tergantung pada kinerja para perilaku organisasi.

Menurut Miner dalam Sutrisno (2011:172-173), indikator kinerja adalah sebagai berikut:

1.Kualitas yang dihasilkan

2.Kuantitas yang dihasilkan

3.Waktu kerja

4.Kerja sama

Berdasarkan tinjauan pustaka yang diuraikan sebelumnya mengenai variabel pelatihan dan disiplin kerja serta pengaruhnya terhadap kinerja karyawan, maka dapat disimpulkan sebagai berikut:

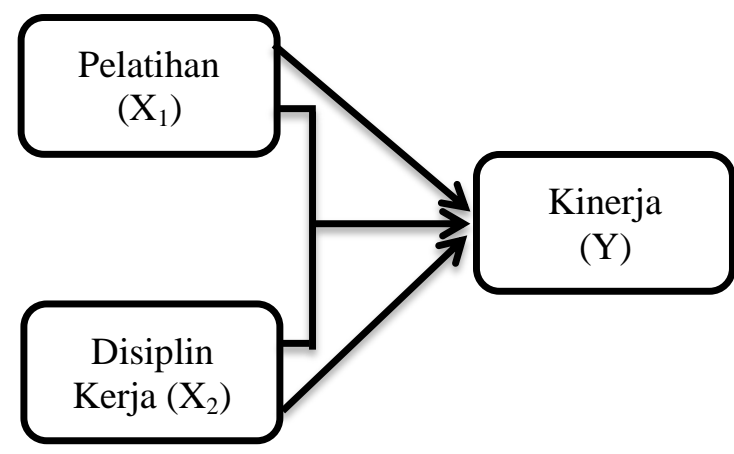

Gambar II.1

Kerangka Konseptual

Hipotesis penelitian adalah jawaban sementara terhadap rumusan masalah penelitian, dimana rumusan masalah penelitian telah dinyatakan dalam bentuk pertanyaan. Berdasarkan kerangka konseptual diatas, maka hipotesis yang diajukan dalam penelitian ini adalah sebagai berikut:

H1: Pelatihan berpengaruh terhadap kinerja karyawan pada PT. Sany Toga Gemilang.

H2: Disiplin kerja berpengaruh terhadap kinerja karyawan pada PT. Sany Toga Gemilang.

H3: Pelatihan dan disiplin kerja berpengaruh terhadap kinerja karyawan pada PT. Sany Toga Gemilang.

\section{HASIL DAN PEMBAHASAN}

Penelitian ini dilakukan di PT. Sani Toga Gemilang Medan berlokasi di Jl. Setia Luhur No. 188 A-B, (TOGA CENTRE), Dwikora, Medan Helvetia.Penelitian ini dilakukan dari bulan Juli 2018 sampai Juli 2019.

Penelitian ini menggunakan kuantitatif.Jenis penelitian yang dilakukan peneliti adalah deskriptif kuantitatif.Penelitian ini bersifat descriptive explanatory.

Dalam penelitian ini yang dijadikan populasi adalah seluruh karyawan tetap perusahaanPT. Sany 
Toga Gemilang, yang berjumlah 186 orang.Sampel penelitian ditentukan dengan rumus Slovin, 127 orang sebagai sampel dan 30 orang diluar sampel untuk uji validitas.

\begin{tabular}{rrr}
\multicolumn{2}{c}{ Defenisi operasional masing- } \\
masing variabelpenelitian & akan
\end{tabular} dijelaskan pada tabel III.4 sebagai berikut:

Tabel III.4

Definisi Operasional Variabel Penelitian

\begin{tabular}{|c|c|c|c|}
\hline Variabel & Definisi variabel & Indikator Variabel & $\begin{array}{c}\text { Skala } \\
\text { Pengukuran }\end{array}$ \\
\hline $\begin{array}{c}\text { Pelatihan } \\
\text { Kerja } \\
\left(\mathrm{X}_{1}\right)\end{array}$ & $\begin{array}{l}\text { Pelatihan adalah proses } \\
\text { mempertahankan atau } \\
\text { memperbaiki keterampilan } \\
\text { karyawan mengahasilkan } \\
\text { perkerjaan yang efektif. } \\
\text { Bangun (2012:201) }\end{array}$ & $\begin{array}{ll}\text { 1. } & \text { Tujuan dan Sasaran } \\
\text { 2. } & \text { Para pelatih } \\
\text { 3. } & \text { Materi pelatihan } \\
\text { 4. } & \text { Metode pelatihan } \\
\text { 5. } & \text { Peserta peathan } \\
\text { Mangkunegara (2013:44) }\end{array}$ & Skala Likert \\
\hline $\begin{array}{c}\text { Disiplin } \\
\text { Kerja } \\
\left(\mathrm{X}_{2}\right)\end{array}$ & 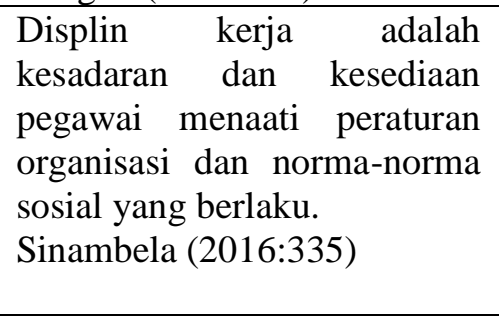 & $\begin{array}{l}\text { 1. Tujuan dan } \\
\text { kemampuan, } \\
\text { 2. Balas jasa, } \\
\text { 3. Keadilan, } \\
\text { 4. Sanksi hukum, } \\
\text { 5. Ketegasan } \\
\text { Hasibuan (2016:194-198) }\end{array}$ & Skala Likert \\
\hline $\begin{array}{l}\text { Kinerja } \\
(\mathrm{Y})\end{array}$ & $\begin{array}{l}\text { Kinerja adalah hasil kinerja } \\
\text { karyawan dilihat pada aspek } \\
\text { kualitas, kuantitas, waktu } \\
\text { kerja dan kerja sama untuk } \\
\text { mencapai tujuan yang telah } \\
\text { ditetapkan oleh organisasi } \\
\text { Sutrisno (2010:172) }\end{array}$ & $\begin{array}{l}\text { 1.Kualitas yang } \\
\text { dihasilkan } \\
\text { 2.Kuantitasyang } \\
\text { dihasilkan } \\
\text { 3. Waktu kerja } \\
\text { 4. Kerja sama } \\
\text { Sutrisno(2011:172-173) }\end{array}$ & Skala Likert \\
\hline
\end{tabular}

\section{Uji Validitas}

Validitas adalah suatu ukuran yang menunjukkan tingkat-tingkat kevalidan atau kesahihan insrumen. Menurut Sugiyono (2005:106), “jika nilai validitas setiap pertanyaan lebih besar dari nilai koefisien korelasi (r) 0,30 makah butir pertanyaan sudah dianggap valid". Berikut hasil pengujian validitas variabel penelitian:

Tabel III.1

Rangkuman Hasil Uji Validitas

\begin{tabular}{|c|c|c|c|}
\hline Variabel & $\begin{array}{c}\text { Jumlah } \\
\text { Item }\end{array}$ & $\begin{array}{c}\text { Jumlah } \\
\text { Valid }\end{array}$ & Keterangan \\
\hline Pelatihan & 10 & 10 & Semua Valid \\
\hline Disiplin Kerja & 10 & 10 & Semua Valid \\
\hline Kinerja & 8 & 8 & Semua Valid \\
\hline
\end{tabular}

Sumber: hasil penelitian 2019, data diolah

\section{Uji Reliabilitas}

Menurut Ghozali (2009:130), reabilitas adalah alat untuk mengukur suatu kuesioner yang merupakan indikator dari variabel atau konstruk. 
Suatu kuesioner dikatakan reliabel atau handal jika jawaban seseorang terhadap pertanyaan adalah konsisten atau stabil dari waktu ke waktu.

Tabel III.1

Rangkuman Hasil Uji Reliabilitas

\begin{tabular}{|c|c|c|c|}
\hline Variabel Penelitian & $\begin{array}{c}\text { Cronbach's } \\
\text { Alpha }\end{array}$ & N of Items & Keterangan \\
\hline Pelatihan $\left(\mathrm{X}_{1}\right)$ & 0,914 & 10 & Reliabel \\
\hline Disiplin Kerja $\left(\mathrm{X}_{2}\right)$ & 0,906 & 10 & Reliabel \\
\hline Kinerja $(\mathrm{Y})$ & 0,905 & 8 & Reliabel \\
\hline
\end{tabular}

Sumber: hasil penelitian 2019, data diolah

Berdasarkan tabel III.7.4 tersebut, dapat dijelaskan bahwa variabel pelatihan memiliki nilai reliabilitas 0,914, variabel disiplin memiliki nilai reliabilitas 0,906 , dan variabel kinerja memiliki reliabilitas

\section{Hasil Uji Asumsi Klasik}

Sebelum melakukan pengujian hipotesis, terlebih dahulu dilakukan pengujian asumsi klasik untuk memastikan bahwa alat uji regresi linier berganda dapat digunakan atau tidak.Apabila uji asumsi klasik telah

\section{Uji Normalitas}

Uji normalitas bertujuan untuk menguji apakah dalam model regresi, variabel pengganggu atau residual berdistribusi normal. Ada dua cara untuk mendeteksi apakah residual berdistribusi normal atau tidak, yaitu

Tabel IV.9

Tabel One Sampel Kolmogorov-Smirnov

One-Sample Kolmogorov-Smirnov Test

\begin{tabular}{|ll|r|}
\hline & & $\begin{array}{r}\text { Unstandardized } \\
\text { Residual }\end{array}$ \\
\hline N & Mean & 127 \\
Normal Parameters ${ }^{\mathrm{a}, \mathrm{b}}$ & Std. Deviation &, 0000000 \\
& Absolute & 2,15154993 \\
Most Extreme Differences & Positive &, 066 \\
& Negative &, 066 \\
& &,- 050 \\
Test Statistic &, 066 \\
Asymp. Sig. (2-tailed) & &, $200^{\mathrm{c}, \mathrm{d}}$ \\
\hline
\end{tabular}



a. Test distribution is Normal.
b. Calculated from data.
c. Lilliefors Significance Correction.
d. This is a lower bound of the true significance.

\section{Sumber: Hasil penelitian 2019}

\begin{abstract}
Berdasarkan Tabel IV.9 diatas, dapat diketahui nilai signifikan (Asymp.Sig) sebesar 0,200, lebih besar dari signifikan $5 \%(0,05)$, maka data tersebut dinyatakan dinyatakan residual berdistribusi normal.
\end{abstract}

\section{Uji Multikolinieritas}

Bertujuan untuk menguji apakah dalam model regresi ditemukan korelasi antar variabel independen hal ini dapat dilihat

\begin{abstract}
dari Variance Inflation Factor (VIF) dengan catatan apabila VIF > 10 maka diduga mempunyai persoalan multikolinieritas dan apabila VIF $<10$ dan nilai tolerance $>0,1$ maka tidak terjadi multikolinieritas. Model regresi yang baik seharusnya tidak terjadi korelasi antara variabel indepen. Hasil pengujian dapat dilihat pada tabel IV.10 berikut ini:
\end{abstract}

Tabel IV.10

Hasil Uji Multikolinieritas

Coefficients $^{\mathrm{a}}$

\begin{tabular}{|c|c|c|c|c|c|c|c|}
\hline \multirow[b]{2}{*}{ Model } & \multicolumn{2}{|c|}{$\begin{array}{c}\text { Unstandardized } \\
\text { Coefficients }\end{array}$} & \multirow{2}{*}{$\begin{array}{c}\text { Standardized } \\
\text { Coefficients } \\
\text { Beta }\end{array}$} & \multirow[b]{2}{*}{$\mathrm{t}$} & \multirow[b]{2}{*}{ Sig. } & \multicolumn{2}{|c|}{ Collinearity Statistics } \\
\hline & $\mathrm{B}$ & Std. Error & & & & Tolerance & VIF \\
\hline $1 \quad$ (Constant) & 3,415 & ,916 & & 3,727 & ,000 & & \\
\hline Pelatihan &, 188 & ,046 & ,256 & 4,084 & ,000 & ,472 & 2,118 \\
\hline Disiplin & ,483 &, 045 &, 674 & 10,773 &, 000 &, 472 & 2,118 \\
\hline
\end{tabular}

a. Dependent Variable: Kinerja

Sumber: Hasil penelitian 2019

Berdasarkan tabel IV.10 tersebut diatas, dapat dijelaskan bahwa nilai tolerance setiap variabel independen $\mathrm{X}_{1}$ sebesar 0,472 dan $\mathrm{X}_{2}$ sebesar 0,472 lebih besar dari 0,1 sedangkan nilai VIF tiap variabel independen $\mathrm{X}_{1}$ dan $\mathrm{X}_{2}$ sebesar 2,118 lebih kecil dari 10, maka data tersebut dinyatakan tidak terjadi gejala multikolinieritas.

\section{Uji Heteroskedastisitas}

Uji heteroskedastisitas bertujuan untuk mengetahui apakah dalam sebuah model regresi suatu penelitian telah terjadi kesamaan variansi residual, jika varians pengamatan tetap maka disebut homokedastisitas dan jika pengamatan berbeda maka disebut heteroskedastisitas. 
Tabel IV.10

Hasil Uji Heteroskedastisitas

\begin{tabular}{|c|c|c|c|c|c|c|}
\hline \multicolumn{7}{|c|}{ Coefficients $^{a}$} \\
\hline \multirow{2}{*}{\multicolumn{2}{|c|}{ Model }} & \multicolumn{2}{|c|}{ Unstandardized Coefficients } & $\begin{array}{c}\text { Standardized } \\
\text { Coefficients }\end{array}$ & \multirow[b]{2}{*}{$\mathrm{t}$} & \multirow[b]{2}{*}{ Sig. } \\
\hline & & $\mathrm{B}$ & Std. Error & Beta & & \\
\hline \multirow[t]{3}{*}{1} & (Constant) & 1,122 &, 504 & & 2,228 & ,028 \\
\hline & Pelatihan & ,027 &, 025 &, 139 & 1,074 & ,285 \\
\hline & Disiplin &,- 002 & ,025 &,- 012 &,- 095 & ,924 \\
\hline
\end{tabular}

a. Dependent Variable: RES 2

Sumber: Hasil penelitian 2019

Berdasarkan tabel IV.11 tersebut dapat dijelaskan bahwa nilai signifikasnsi tiap variabel independen $\mathrm{X}_{1}$ sebesar 0,285 dan $\mathrm{X}_{2}$ sebesar 0,924 lebih besar dari nilai signifikansinya 0,05 maka data terbebas dari masalah heteroskedastisitas.

\section{Analisis Persamaan Regresi Linier Berganda}

Model analisis ini digunakan untuk mengetahui pengaruh variabel independen terhadap variabel dependen.Hasil koefisien regresi linier

Tabel IV.12

Hasil Uji Regresi Linier Berganda

Coefficients $^{\mathrm{a}}$

\begin{tabular}{|c|c|c|c|c|c|}
\hline \multirow[b]{2}{*}{ Model } & \multicolumn{2}{|c|}{ Unstandardized Coefficients } & \multirow{2}{*}{$\begin{array}{c}\begin{array}{c}\text { Standardized } \\
\text { Coefficients }\end{array} \\
\text { Beta }\end{array}$} & \multirow[b]{2}{*}{$\mathrm{t}$} & \multirow[b]{2}{*}{ Sig. } \\
\hline & $\mathrm{B}$ & Std. Error & & & \\
\hline 1 (Constant) & 3,415 & ,916 & & 3,727 & ,000 \\
\hline Pelatihan & ,188 &, 046 & ,256 & 4,084 &, 000 \\
\hline Disiplin & ,483 &, 045 & 674 & 10,773 &, 000 \\
\hline
\end{tabular}

a. Dependent Variable: Kinerja

Sumber: Hasil penelitian 2019

Berdasarkan Tabel IV.12 dapat diperoleh persamaan regresi linier berganda sebagai berikut:

$$
Y=3,415+0,188 X_{1}+0,483 X_{2}
$$

Dari persamaan regresi linier berganda diatas dapat dijelaskan hal-hal sebagai berikut:

1. Nilai konstanta (a) sebesar 3,415 artinya bahwa jika tidak terdapat berganda variabel-variabel independen (X) terhadap variabel $\mathrm{Y}$ dapat dilihat padatabel berikut ini. 
setiap kenaikan variabel pelatihan 1 satuan, maka nilai variabel kinerja akan naik sebesar 0,188 satuan.

3. Variabel disiplin kerja sebesar 0,483 bernilai positif yang artinya

\section{Koefisien Determinansi Hipotesis $\left(\mathbf{R}^{2}\right)$}

Koefisien determinansi $\left(\mathrm{R}^{2}\right)$ digunakan untuk mengukur seberapa jauh kemampuan model dalam menerangkan variansi variabel dependen, dimana nilai $\mathrm{R}^{2}$ berkisar antara $0<\mathrm{R}^{2}<1$.Semakin besar nilai bahwa setiap kenaikan variabel disiplin kerja 1 satuan, maka nilai variabel kinerja akan naik sebesar 0,483 satuan.

Tabel IV.13

Nilai Koefisien Determinansi (R square)

\begin{tabular}{|l|c|r|r|c|}
\multicolumn{5}{|c|}{ Model Summary } \\
\hline Model & $\mathrm{R}$ & $\mathrm{R}$ Square & $\begin{array}{c}\text { Adjusted R } \\
\text { Square }\end{array}$ & $\begin{array}{c}\text { Std. Error of the } \\
\text { Estimate }\end{array}$ \\
\hline 1 &, $878^{\mathrm{a}}$ &, 771 &, 767 & 2,169 \\
\hline
\end{tabular}

a. Predictors: (Constant), Disiplin, Pelatihan

\section{Sumber: Hasil penelitian 2019}

Berdasarkan tabel IV.13 diatas, nilai adjusted $R$ square adalah 0,767 yang artinya bahwa kemampuan variansi varibel pelatihandan disiplin kerja dapat menjelaskan variansi kinerja adalah sebesar $76,7 \%$ dan sisanya

\section{Pengujian Hipotesis Secara Simultan (Uji F)}

Uji F atau uji simultan dilakukan untuk mengetahui pengaruh atau hubungan positif dan signifikansi variabel bebas yaitu pelatihan dan koefisien determinansi, maka semakin baik kemampuan varian dan variabel bebas menerangkan variabel terikat. Nilai koefisien determinansi ditentukan dengan nilai $\mathrm{R}$ square yang dapat dilihat pada tabel berikut ini:

Tabel IV.14

$23,3 \%$ merupakan variabel lain yang tidak diteliti dalam penelitian ini seperti lingkungan kerja fisik dan non fisik, seleksi, kompensasi, kompetensi, pengawasan, sress kerja dan lain sebagainya.

\section{Hasil Uji F}

ANOVA $^{\mathrm{a}}$

\begin{tabular}{|rr|r|r|r|r|r|}
\hline \multicolumn{1}{|l|}{ Model } & Sum of Squares & df & Mean Square & \multicolumn{1}{c|}{ F } & Sig. \\
\hline 1 & Regression & 1959,355 & 2 & 979,677 & 208,272 & \multirow{2}{*}{$000^{\mathrm{b}}$} \\
& Residual & 583,275 & 124 & 4,704 & & \\
& Total & 2542,630 & 126 & & & \\
\hline
\end{tabular}

Sumber: Hasil penelitian 2019

disiplin kerja terhadap variabel terikat yaitu kinerja. Model hipotesis yang digunakan dalam uji $F$ ini adalah sebagai berikut: 
Berdasarkan tabel IV.14 diatas, dapat dilihat bahwa nilai $F_{\text {hitung }}$ adalah sebesar 208,272 sedangkan $F_{\text {tabel }}$ sebesar 3,07. Dari hasil ini diketahui $F_{\text {hitung }}>$ $F_{\text {tabel }}$ dan signifikansi $0,000<0,05$, maka hasil penelitian menunjukkan

\section{Pengujian Hipotesis Secara Parsial (Uji t)}

Uji parsial (uji t) dilakukan untuk menguji secara parsial variabel bebas yang terdiri dari disiplin kerja dan pelatihan mempunyai pengaruh yang

Tabel IV.15

Hasil Uji t Hipotesis

\begin{tabular}{|c|c|c|c|c|c|c|}
\hline \multicolumn{7}{|c|}{ Coefficients $^{a}$} \\
\hline \multirow{2}{*}{\multicolumn{2}{|c|}{ Model }} & \multicolumn{2}{|c|}{ Unstandardized Coefficients } & \multirow{2}{*}{$\begin{array}{c}\text { Standardized } \\
\text { Coefficients } \\
\text { Beta }\end{array}$} & \multirow[b]{2}{*}{$\mathrm{t}$} & \multirow[b]{2}{*}{ Sig. } \\
\hline & & $\mathrm{B}$ & Std. Error & & & \\
\hline \multirow[t]{3}{*}{1} & (Constant) & 3,415 & ,916 & & 3,727 &, 000 \\
\hline & Pelatihan & 188 & ,046 & ,256 & 4,084 & ,000 \\
\hline & Disiplin & ,483 &, 045 & 674 & 10,773 &, 000 \\
\hline
\end{tabular}

bahwa secara simultan $\mathrm{H}_{1}$ diterima dan $\mathrm{H}_{0}$ ditolak. Hal ini menunjukkan bahwa disiplin kerja dan pelatihan berpengaruh positif dan signifikan terhadap kinerja karyawan pada PT. Sany Toga Gemilang. positif dan signifikan terhadap kinerja karyawan pada PT. Sany Toga Gemilang.

a. Dependent Variable: Kinerja

Sumber: Hasil penelitian 2019

Berdasarkan tabel IV.15 diatas, diperoleh hasil:

1. Uji hipotesis parsial variabel pelatihan dari tabel tersebut dapat dilihat nilai $t_{\text {hitung }}$ variabel pelatihan $\left(\mathrm{X}_{1}\right)$ adalah sebesar 4,084 dengan signifikan 0,000 maka hasil penelitian menunjukkan hipotesis $\mathrm{H}_{1}$ diterima karena $\mathrm{t}_{\text {hitung }}>\mathrm{t}_{\text {tabel }}$ $(4,084>1,979)$ dan signifikan lebih kecil dari 0,05 yang berarti bahwa variabel pelatihan berpengaruh positif dan signifikan terhadap variabel kinerja karyawan pada PT. Sany Toga Gemilang.

\section{KESIMPULAN DAN SARAN}

Dari hasil penelitian dan pembahasan, maka dapat ditarik kesimpulan sebagai berikut:
2. Uji hipotesis parsial variabel disiplin kerja dari tabel tersebut dapat dilihat nilai $t_{\text {hitung }}$ variabel disiplin kerja $\left(\mathrm{X}_{2}\right)$ adalah sebesar 10,773 dengan nilai signifikan 0,000 maka hasil penelitian menunjukkan hipotesis $\mathrm{H}_{1}$ diterima karena $t_{\text {hitung }}>t_{\text {tabel }}(10,773>1,979)$ dan signifikan lebih kecil dari 0,05 yang berarti bahwa variabel disiplin kerja berpengaruh positif dan signifikan terhadap variabel kinerja karyawan pada PT. Sany Toga Gemilang.

1. Hasil pengujian secara parsial menunjukkan bahwa pelatihan berpengaruh positif dan signifikan 
terhadap kinerja karyawan PT. Sany Toga Gemilang.

2. Hasil pengujian secara parsial menunjukkan bahwa disiplin kerja berpengaruh positif dan signifikan terhadap kinerja karyawan pada PT. Sany Toga Gemilang.

3. Hasil pengujian secara simultan menunjukkan bahwa pelatihan dan disiplin kerja berpengaruh signifikan terhadap kinerja karyawan pada PT. Sany Toga Gemilang. Nilai koefisien determinansi adjusted $R^{2}$ dari pelatihan dan disiplin kerja menjelaskan variabel kinerja karyawan pada PT. Sany Toga Gemilang sebesar 76,7\% dan sisanya $23,3 \%$ dijelaskan oleh variabel-variabel independen lain yang tidak diteliti.

Adapun saran yang ingin penulis sampaikan berdasarkan kesimpulan sebelumnya adalah sebagai berikut:

1. Bagi peneliti

Dengan penelitian yang dilakukan ini maka peneliti berharap dapat memperoleh lebih banyak pengetahuan mengenai pengaruh pelatihan dan disiplin kerja

\section{DAFTAR PUSTAKA}

Bafadal, Ibrahim.

(2011). Pengelolaan Perpustakaan Sekolah. Jakarta: Bumi Aksara.

Bangun, Wilson. 2012. Manajemen Sumber Daya Manusia. Jakarta: Erlangga

Burhanuddin, Amalia Rizky, 2015. Analisis Penggunaan

Metode Altman Z- $\quad$ Score dan Metode Springate Untuk Mengetahi Potensi

Terjadinya Financial

Distress Pada Perusahaan Manufaktur Sector Industry terhadap kinerja karyawan dalam sebuah perusahaan.

2. Bagi Program studi S1 Manajemen Fakultas Ekonomi

Dengan penelitian yang dilakukan ini diharapkan dapat menambah jumlah hasil karya mahasiswa yang dapat dijadikan refrensi yang baik bagi peneliti selanjutnya.

3. Bagi PT. Sany Toga Gemilang

Diharapkan PT. Sany Toga Gemilang dapat memperbaiki peraturan serta mempertegas sanksi bagi karyawan yang melanggar aturan perusahaan sehingga disiplin kerja dapat meningkat serta memperbaiki kegiatan pelatihan kerja sehingga hasil pemberian pelatihan kerja dapat membuat karyawan lebih mengerti pekerjaannya dan mampu mengerjakan pekerjaan dengan lebih baik.

4. Bagi peneliti selanjutnya

Sebagai bahan acuan dan agar dapat diamati variabel lainnya yang dapat mempengaruhi kinerja karyawan seperti motivasi, seleksi, kompensasi, pengawasan dan sebagainya.

\section{Dasar Dan Kimia Sub Sector Semen Periode 2009. 2013.}

Darmawan, H. Didit. 2013. Prinsipprinsip Perilaku Organisasi. Surabaya: Pena Semesta.

Ghozali, Imam. 2009. Aplikasi Analisis Multivate dengan Program SPSS. Semarang: UNDIP

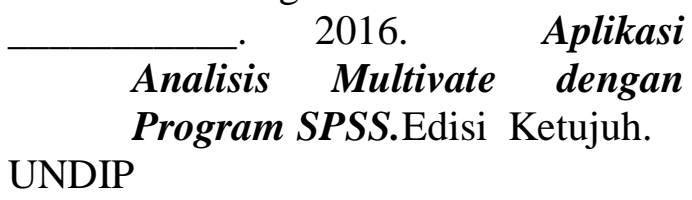


Hamali, Arif Yusuf. 2016. Pemahaman Sumber Daya Manusia. Yogyakarta:

CAPS.

Handoko. 2014.Manajemen Personalia dan Sumber Daya Manusia. Yogyakarta: BPFEYOGYAKARTA.

Hartatik, Indah Puji. 2014. Buku Praktis Mengembangkan SDM. Yokyakarta: Laksana

Hasibuan, Malayu S. P. 2009. Manajemen Sumber Daya Manusia. Jakarta:Bumi Aksara. 2013. Manajemen Sumber Daya Manusia. Jakarta: PT. Bumi Aksara.

2016. Manajemen

Sumber Daya Manusia. Jakarta: PT. Bumi Aksara.

Kasmir.2016. Analisis

Laporan

Keuangan.Jakarta:

Raja

Grafindo Persada.

Mangkunegara. 2011. Manajemen

Sumber Daya Manusia

Perusahaan. Bandung. PT.

Remaja Rosda Karya.

\section{Manajemen}

Sumber Daya Manusia

Perusahaan. Bandung: PT

Remaja Rosdakarya.

$$
\text { 2017. Manajemen }
$$

Sumber Daya Manusia

Perusahaan. Bandung: PT

Remaja Rosdakarya.

\begin{tabular}{|c|c|c|}
\hline Sumber & $\begin{array}{l}2018 . \\
\text { Daya }\end{array}$ & $\begin{array}{r}\text { Ianajemen } \\
\text { Manusia }\end{array}$ \\
\hline $\begin{array}{l}\text { Perusahaan. } \\
\text { Remaja Rosd }\end{array}$ & $\begin{array}{l}\text { Bandun } \\
\text { dakarya. }\end{array}$ & \\
\hline $\begin{array}{l}\text { oeheriono, } \\
\text { Kinerja }\end{array}$ & 2012.Pe & $\begin{array}{r}\text { ngukuran } \\
\text { Berbasis }\end{array}$ \\
\hline Kompetensi. & Edisi & \\
\hline Jakarta: PT & Raja & Gra \\
\hline
\end{tabular}

Mulyadi. 2015. Akuntansi Biaya, Edisi 5. Yogyakarta : Sekolah Tinggi Ilmu Manajemen YKPN.
Rachmawati Kusdyah. 2008. Manajemen Sumber Daya Manusia. Yogyakarta.

ANDI

Rivai, Veithzal dan Sagala, Ella Jauvani. 2013. Manajemen Sumber Daya Manusia Untuk Perusahaan. Cetakan Kelima. Jakarta: PT. Raja Grafindo Persada

Samsudin, Sadili. (2010). Manajemen Sumber Daya Manusia. Bandung: Pustaka Setia

Sinambela, Poltak. Lijan. 2016. Manajemen Sumber Daya Manusia. Jakarta: PT Bumi Aksara

Soewadji, Jusuf. 2012. Pengantar Metodologi Peneletian, Jakarta : Mitra Wacana Media.

Sugiyono.2005. Metode Penelitian Bisnis. Bandung: Alfabeta . 2010. Metode Penelitian

Pendidikan Pendekatan Kuantitatif, Kualitatif, dan $\boldsymbol{R} \& \boldsymbol{D}$. Bandung: Alfabeta. 2012. Metode Penelitian Kuantitatif Kualitatif dan $\boldsymbol{R} \& \boldsymbol{D}$. Bandung: $\quad$ Alfabeta. 2015.Metode Penelitian Bisnis. Bandung: CV Alfabeta. .2016. Metode Penelitian

Kuantitatif Kualitataif dan Kombinasi (Mixed

Methods). Bandung: Alfabeta.

Sunyoto, Danang. 2013. Manajemen Sumber Daya Manusia. Yogyakarta: Center

for Academic Publishing Service.

Sutrisno, Edy.2009. Manajemen Sumber Daya Manusia. Jakarta: Kencana Prenada Media Group.

$\begin{array}{ccr}2010 . & \text { Manajemen } \\ \text { Sumber } & \text { Daya } & \text { Manusia. }\end{array}$


Jakarta: Kencana Prenada Media Group.

2011. Manajemen

Sumber Daya Manusia.

Jakarta: Kencana

2015. Manajemen

Sumber Daya Manusia
(Cetakan ke tujuh). Jakarta:

Kencana Prenada Media Group.

Zainal. 2014. Model-model, Media,

dan Strategi Pembelajaran

Kontekstual (Inovatif).

Bandung: Yrama Widya. 